\title{
Evidences of Seasonal Variation in Altimetry Derived Ocean Tides in the Subarctic Ocean
}

\author{
Hok Sum Fok ${ }^{1, *}$, C. K. Shum ${ }^{1,2}$, Yuchan $\mathrm{Yi}^{1}$, Alexander Braun ${ }^{3}$, and H. Baki $\mathrm{Iz}^{4}$ \\ ${ }^{1}$ Division of Geodetic Science, School of Earth Sciences, Ohio State University, Columbus, Ohio, USA \\ ${ }^{2}$ Institute of Geodesy and Geophysics, Chinese Academy of Sciences, Wuhan, China \\ ${ }^{3}$ Department of Geosciences, University of Texas at Dallas, Dallas, Texas, USA \\ ${ }^{4}$ Department of Land Surveying and Geo-Informatics, Hong Kong Polytechnic University, Kowloon, Hong Kong
}

Received 6 April 2012, accepted 16 November 2012

\begin{abstract}
While the barotropic ocean tides in the deep ocean are well modeled to $\sim 2 \mathrm{~cm}$ RMS, accurate tidal prediction in the icecovered polar oceans and near coastal regions remain elusive. A notable reason is that the most accurate satellite altimeters (TOPEX/Jason-1/-2), whose orbits are optimized to minimize the tidal aliasing effect, have spatial coverage limited to largely outside of the polar ocean. Here, we update the assessment of tidal models using 7 contemporary global and regional models, and show that the altimetry sea surface height ( $\mathrm{SSH}$ ) anomaly residual after tidal correction is $9-12 \mathrm{~cm}$ RMS in the Subarctic Ocean. We then address the hypothesis whether plausible evidence of variable tidal signals exist in the seasonally ice-covered Subarctic Ocean, where the sea ice cover is undergoing rapid thinning. We first found a difference in variance reduction for multi-mission altimeter SSH anomaly residuals during the summer and winter seasons, with the residual during winter season 15 - 30\% larger than that during the summer season. Experimental seasonal ocean tide solutions derived from satellite altimetry reveals that the recovered winter and summer tidal constituents generally differ by a few $\mathrm{cm}$ in amplitude and tens of degrees in phase. Relatively larger seasonal tidal patterns, in particular for $\mathrm{M}_{2}, \mathrm{~S}_{2}$ and $\mathrm{K}_{1}$ tides, have been identified in the Chukchi Sea study region near eastern Siberia, coincident with the seasonal presence and movement of sea ice.
\end{abstract}

Key words: Seasonal ocean tides, Satellite altimetry, Subarctic Ocean

Citation: Fok, H. S., C. K. Shum, Y. Yi, A. Braun, and H. B. Iz, 2013: Evidences of seasonal variation in altimetry derived ocean tides in the Subarctic Ocean. Terr. Atmos. Ocean. Sci., 24, 605-613, doi: 10.3319/TAO.2012.11.16.01(TibXS)

\section{INTRODUCTION}

The advent of satellite radar altimetry, introduced in the 1970s (GEOS-3 and Seasat), provided a synoptic means of observing the global ocean surface and other surface topographic heights with weekly temporal sampling, and with cross-track resolution of $\sim 100 \mathrm{~km}$ at the equator. This initiative was driven by our limited knowledge and understanding of the global general ocean circulation, because it is difficult to have globally covered in-situ hydrographic or other oceanographic measurements. The launch of TOPEX/ POSEIDON in the beginning of the 1990s represents a new era of satellite altimetry to advance satellite oceanography and tidal science, owing to its near-global coverage, unprecedented accuracy, optimal orbital configuration to minimize

\footnotetext{
* Corresponding author

E-mail:fok.8@osu.edu
}

tidal and seasonal signal aliasing, and adequate spatial and temporal sampling for general circulation studies (Fu et al. 1994; Shum et al. 1995). Other missions, ERS-1/-2, GFO, Envisat, Jason-1/-2, and Cryosat-2, have been launched to lengthen the geophysical and oceanographic time series to longer than two decades, in particular for the study of ocean's role in climate change, including sea-level rise, general ocean circulation and heat transport.

While global ocean tides models derived from satellite altimetry in the deep ocean are known to have accuracy of $\sim 2 \mathrm{~cm}$ RMS, their uncertainties increase significantly near coastal regions, in high-latitude Ocean or over shallow seas (Shum et al. 1997, 2001), and that the model accuracies are region-dependent, with larger uncertainties in regions of energetic ocean dynamics. The percentage of sea surface height $(\mathrm{SSH})$ variability explained by ocean tides, which 
should account for $\sim 80 \%$ SSH variability, could be quite different depending on regional characteristics (Fok et al. 2010), primarily due to non-linear processes triggered by complicated bathymetry (Ray et al. 2011). Note that most global ocean tide models are derived up to $\pm 66^{\circ}$ due to the limitation of the TOPEX-class altimetric satellite orbital inclinations and the undesirable tidal aliasing effect of GFO, ERS and Envisat because of their respective orbits.

The Arctic Ocean is the smallest and shallowest of the world's five major oceanic divisions, which is almost completely surrounded by Eurasia and North America (Pidwirny 2006). The Arctic region is particularly sensitive to climate variability and is in the midst of a major climate, environmental and societal change. In particular, Arctic sea ice is sensitive to small changes in vertical oceanic heat flux and has undergone rapid thinning during the past decades (Holloway and Sou 2002; Kwok and Untersteiner 2011). The sea ice cover and its change or diminishment represents a benchmark of assessing large-scale climate changes (Renganathan 2010). The effect of ocean circulation on sea ice through ocean-sea ice coupled modeling, its feedback and relationship to the conservation of heat, fresh water, and salinity (Hibler III and Bryan 1984; Campin et al. 2008), are all critical processes related to climate change in the Arctic Ocean. The exact measurements of sea ice freeboard height change using satellite laser or radar altimetry requires accurate knowledge of dynamic ocean topography, the geoid, and ocean tides (Renganathan 2010; Kwok and Untersteiner 2011). The latter is the focus of this study.

There are evidences that seasonally sea-ice-covered ocean causes seasonality in tidal signals (Renganathan 2010), which would affect the accuracy of sea ice freeboard height change retrieval using satellite altimetry. In addition to sea ice, it is found that significant seasonal modulation of ocean tides exist over the European shelf, as revealed by TOPEX altimeter and tide gauge data (Leeuwenburgh et al. 1999; Huess and Andersen 2001). Ray (2006) reported secular increases of $\mathrm{M}_{2}$ tidal amplitude in the Gulf of Maine during the $20^{\text {th }}$ century, however, the amplitudes abruptly dropped in the early 1980s.

Recent model simulations have been conducted to study the ice drift and ice-induced change effects on $\mathrm{M}_{2}$ tide and its dynamics covering all parts of the Arctic Ocean above $65^{\circ}$ latitude. A study claimed that the sea ice cover has a substantial effect on the $\mathrm{M}_{2}$ tide. This generally causes a decrease in $\mathbf{M}_{2}$ tidal amplitudes and an increase in tidal phases and hence changing the tidal characteristics and its energy dissipation (Kagan et al. 2008). A more recent model simulation study on the seasonal variations of $\mathrm{M}_{2}$ tide in the Arctic Ocean concluded that the tidal amplitude and phase during the summer and winter seasons differs by a few $\mathrm{cm}$ and tens of degrees, respectively (Kagan et al. 2011).

However, the aforementioned studies are limited to either the seasonal modulation of $\mathrm{M}_{2}$ tidal constituent in the
European Shelf where strong tidal mixing and surge are present, or to the use of tidal hydrodynamic models to simulate and examine seasonal variations in $\mathrm{M}_{2}$ tide. Here we use SSH observations from multi-mission satellite altimetry over the polar ocean, 1992 - 2010, with distinct spatial and temporal coverage, to conduct empirical ocean tide modeling and to test the hypothesis for the existence of seasonal tidal signal. Yi et al. (2006) investigated the feasibility of an empirical ocean tide modeling solution using GFO and Envisat around Antarctica Ocean and showed a comparable accuracy with the TPXO6.2 and FES2004 models, which are hydrodynamic models with data assimilation at latitude higher than $\pm 66^{\circ}$. This contribution provides a solid foundation for this study.

This paper aims to study plausible evidences of the potential seasonality of ocean tides in the Subarctic Ocean. Due primarily to the seasonal or permanent sea ice cover, large part of the Arctic Ocean, greater than $72^{\circ}$ latitude, are at present without accurate altimetry data because of a variety of reasons, including sea ice contamination of altimeter waveforms, lack of accurate mean sea surface model to allow gradient corrections to retrieve altimetric sea surface topography heights (Cheng et al. 2012). Therefore, we limit our study at latitudes between $60^{\circ}$ and $72^{\circ}$ in the Subarctic Ocean. Particular emphasis is paid on the Chukchi Sea region near eastern Siberia, where there is a substantial amount of sea ice during the winter season and primarily ice-free during summer season, but with adequate altimeter data to conduct the tidal analysis study.

\section{SEASONAL VARIATION OF OCEAN TIDES IN THE SUBARCTIC OCEAN}

To possibly detect the seasonal variation in ocean tides, SSH anomaly variance reduction test is conducted at latitude between $60^{\circ}$ and $72^{\circ}$ in the Subarctic Ocean. This method applies the tidal height prediction from ocean tide models for the correction to the sea surface height (SSH) anomaly for each type of altimeter data, with the implicit assumption that the variance reduction ability by ocean tide models is different during the summer and winter seasons. The analysis used altimeter data of TOPEX, Jason-1, GFO, and Envisat. The SSH anomaly data are from TOPEX cycles 4 - 364, TOPEX Tandem Interleave Mission (TTM) cycles 369 - 479, Jason-1 cycles 1 - 303, GFO cycles 37 204, and Envisat cycles 10 - 80. Preprocessing of those data were made through the update and retrieval of the so-called stackfile system, in which the data are gradient-corrected, edited and post-processed (Kruizinga 1997; Yi 2010). Seven global and regional ocean tide models are used in this study: DTU10 (Cheng and Andersen 2011), EOT11a (Bosch and Savcenko 2008), FES2004 (Lyard et al. 2006), GOT4.7 (Ray 1999), NAO.99b (Matsumoto et al. 2000), TPXO7.2 (Egbert and Erofeeva 2002), and the AOTIM-5 regional tide 
model (Padman and Erofeeva 2004). The AOTIM-5 model is included in this study because it is a regional Arctic ocean tide model as compared to other global tide models used here.

The standard deviation of the along-track SSH anomaly and the SSH anomaly residual after tidal height removal predicted by various ocean tide models over the Subarctic Ocean are computed to investigate the difference in variance reduction between the summer and winter seasons. Note that we define the summer season between March and September, and the winter season between September and March. The SSH anomaly residual is defined as:

\section{SSH anomaly residual $=$}

SSH anomaly - (diurnal + semidiurnal tides) - LP

where the diurnal and semidiurnal tides are predicted by each of the ocean tide models, and the long-period (LP) equilibrium tides are calculated based on Cartwright and Edden (1973) (which was adopted in the GOT00.2 and GOT4.7 models) for consistency. Note also that SSH anomaly residual larger than $50 \mathrm{~cm}$ was excluded in the statistics. All tide models did not use Jason-2 altimetry data in the solution, except for the DTU10 and the EOT11a models. In other words, Jason-2 data are not independent in the evaluations of these two tide models.

Table 1 shows the overall SSH anomaly variation for an assessment of consistency among contemporary global ocean tide models, in terms of standard deviation (Stdev) for each altimeter and Root Sum of Squares (RSS) Stdev of the SSH anomaly for the entire altimeter data before and af- ter ocean tide correction, respectively. Variance Explained (VE) by ocean tide correction for the entire region is also shown. Similar statistics was shown in Tables $2 \mathrm{a}$ and $\mathrm{b}$ respectively for summer and winter seasons, excluding the AOTIM-5 regional model. Bold values in Tables 1 and 2 are associated with the tide models with the best performance in each of the cases (columns).

All 6 global ocean tide models, together with the experimental Arctic ocean tide model developed in this study, exhibit similar performance, except for the AOTIM-5 regional model which has worse performance (Table 1). Multi-mission altimetry SSH anomaly residual after tidal corrections using the 7 global and regional tide models is at $9-12 \mathrm{~cm}$ (the regional model AOTIM is excluded in the residual computation) in the Subarctic Ocean (Table 1). As a qualitative comparison, the estimated discrepancy among a number of earlier global ocean tide models in the deep ocean is $2-3 \mathrm{~cm}$ (Shum et al. 2001).

Tables $2 \mathrm{a}$ and $\mathrm{b}$ both show substantial differences in SSH anomaly residuals after corrections using various tide models during the summer and winter seasons. Better SSH anomaly variance reduction, as manifested from the bold values, is also evident for the tide model derived from multialtimetry data during the summer (i.e., this study, Summer Model) and the winter (i.e., this study, Winter Model) seasons. The variation in SSH anomaly during the summer season is lower than that in winter by $15-30 \%$, regardless of whether it is before or after ocean tide correction. This is particularly evident in the TOPEX and Jason-1 interleave, and Jason-2 altimeter data. The Jason-2 along track SSH anomaly residual variation during the summer and winter

Table 1. Standard deviations of SSH anomaly residuals for the empirical seasonal ocean tide model along satellite tracks in the Subarctic Ocean (in $\mathrm{cm}$ ) for entire data without separation into summer and winter seasons.

\begin{tabular}{|c|c|c|c|c|c|c|c|c|c|}
\hline \multirow[b]{2}{*}{ Model } & \multicolumn{7}{|c|}{ Stdev (after) } & \multirow{2}{*}{$\begin{array}{c}\text { RSS } \\
\text { Stdev (after) }\end{array}$} & \multirow[b]{2}{*}{$\operatorname{VE}(\%)$} \\
\hline & $\begin{array}{c}\text { TOPEX/ } \\
\text { POSEIDON }\end{array}$ & $\begin{array}{c}\text { TOPEX } \\
\text { Interleave }\end{array}$ & GFO & Envisat & $\begin{array}{c}\text { Jason-1 } \\
\text { Interleave }\end{array}$ & Jason-1 & Jason-2 & & \\
\hline Stdev (before) & 55.67 & 53.56 & 47.53 & 48.54 & 52.82 & 54.92 & 55.91 & & \\
\hline DTU10* & 10.23 & 9.14 & 10.12 & 9.84 & 11.93 & 9.28 & 11.21 & 27.23 & 80.51 \\
\hline EOT11a* & 10.33 & 9.15 & 10.30 & 9.86 & 11.91 & 9.32 & 11.24 & 27.36 & 80.41 \\
\hline FES2004 & 10.42 & 9.26 & 10.50 & 10.04 & 12.02 & 9.48 & 11.51 & 27.78 & 80.11 \\
\hline GOT4.7 & 10.27 & 9.14 & 10.10 & 9.85 & 11.90 & 9.27 & 11.24 & 27.24 & 80.50 \\
\hline NAO.99b & 10.58 & 9.33 & 10.96 & 10.33 & 11.89 & 9.43 & 11.43 & 28.05 & 79.92 \\
\hline TPXO.7.2 & 10.30 & 9.22 & 10.53 & 10.13 & 11.89 & 9.32 & 11.27 & 27.57 & 80.27 \\
\hline AOTIM5 & 26.47 & 26.33 & 24.96 & 24.45 & 27.65 & 26.31 & 26.27 & - & - \\
\hline This study & 10.43 & 8.95 & 9.94 & 9.69 & 12.01 & 9.17 & 11.28 & 27.15 & 80.56 \\
\hline
\end{tabular}

* Model used Jason-2 data for ocean tide solutions. Bold values indicate the lowest residual and better overall variance reduction for the respective test. 
Fok et al.

Table 2 .

\begin{tabular}{|c|c|c|c|c|c|c|c|c|c|}
\hline \multirow[b]{2}{*}{ Model } & \multicolumn{7}{|c|}{ Stdev (after) } & \multirow{2}{*}{$\begin{array}{c}\text { RSS } \\
\text { Stdev (after) }\end{array}$} & \multirow[b]{2}{*}{ VE (\%) } \\
\hline & $\begin{array}{c}\text { TOPEX/ } \\
\text { POSEIDON }\end{array}$ & $\begin{array}{c}\text { TOPEX } \\
\text { Interleave }\end{array}$ & GFO & Envisat & $\begin{array}{c}\text { Jason-1 } \\
\text { Interleave }\end{array}$ & Jason-1 & Jason-2 & & \\
\hline Stdev (before) & $\mathbf{5 5 . 3 7}$ & 53.06 & 47.14 & 48.19 & 51.66 & 54.88 & 55.13 & & \\
\hline DTU10* & 9.32 & 8.54 & 9.08 & 9.14 & 9.96 & 8.58 & 9.78 & 24.38 & 82.38 \\
\hline EOT11a* & 9.45 & 8.51 & 9.34 & 9.16 & 9.99 & 8.61 & 9.86 & 24.57 & 82.24 \\
\hline FES2004 & 9.56 & 8.63 & 9.57 & 9.39 & 10.15 & 8.81 & 10.25 & 25.13 & 81.84 \\
\hline GOT4.7 & 9.37 & 8.49 & 9.00 & 9.14 & 9.95 & 8.53 & 9.82 & 24.34 & 82.41 \\
\hline NAO.99b & 9.68 & 8.71 & 9.94 & 9.67 & 9.78 & 8.69 & 9.89 & 25.12 & 81.85 \\
\hline TPXO.7.2 & 9.42 & 8.59 & 9.51 & 9.46 & 9.94 & 8.64 & 9.84 & 24.75 & 82.11 \\
\hline This study & 9.48 & 8.27 & 9.01 & 9.11 & 10.02 & 8.44 & 9.91 & 24.33 & 82.42 \\
\hline This study (Summer Model) & 9.49 & 8.14 & 8.96 & 9.04 & 10.09 & 8.42 & 10.07 & 24.34 & 82.41 \\
\hline \multicolumn{10}{|c|}{ RSS Stdev $($ before $)=138.37 \mathrm{~cm}$} \\
\hline \multicolumn{10}{|c|}{ (b) Standard deviations of SSH anomaly residuals for ocean tide models along satellite tracks in the subarctic ocean (in $\mathrm{cm}$ ) during winter season } \\
\hline \multirow[b]{2}{*}{ Model } & \multicolumn{7}{|c|}{ Stdev (after) } & \multirow[b]{2}{*}{$\begin{array}{c}\text { RSS } \\
\text { Stdev (after) }\end{array}$} & \multirow[b]{2}{*}{$\mathrm{VE}(\%)$} \\
\hline & $\begin{array}{c}\text { TOPEX/ } \\
\text { POSEIDON }\end{array}$ & $\begin{array}{c}\text { TOPEX } \\
\text { Interleave }\end{array}$ & GFO & Envisat & $\begin{array}{c}\text { Jason-1 } \\
\text { Interleave }\end{array}$ & Jason-1 & Jason-2 & & \\
\hline Stdev (before) & 56.26 & 54.57 & 48.20 & 47.56 & 54.73 & 55.15 & 56.86 & & \\
\hline DTU10* & 10.94 & 9.59 & 10.87 & 10.10 & 13.18 & 9.85 & 12.17 & 29.17 & 79.37 \\
\hline EOT11a* & 11.01 & 9.65 & 10.97 & 10.11 & 13.13 & 9.90 & 12.17 & 29.25 & 79.32 \\
\hline FES2004 & 11.08 & 9.75 & 11.15 & 10.24 & 13.21 & 10.03 & 12.34 & 29.57 & 79.09 \\
\hline GOT4.7 & 10.96 & 9.64 & 10.89 & 10.07 & 13.12 & 9.89 & 12.18 & 29.18 & 79.36 \\
\hline NAO $.99 b$ & 11.28 & 9.81 & 11.68 & 10.44 & 13.24 & 10.05 & 12.42 & 29.99 & 78.79 \\
\hline ТРX0.7.2 & 10.99 & 9.69 & 11.27 & 10.31 & 13.12 & 9.90 & 12.23 & 29.45 & 79.17 \\
\hline This study & 11.03 & 9.40 & 10.83 & 10.02 & 13.24 & 9.70 & 12.27 & 29.12 & 79.41 \\
\hline This study (Winter Model) & 11.19 & 9.46 & 10.70 & 9.90 & 13.27 & 9.78 & 12.35 & 29.17 & 79.37 \\
\hline
\end{tabular}

* Model used Jason-2 data for ocean tide solutions. Bold values indicate the lowest residual and better overall variance reduction for the respective test.

seasons are also illustrated (Fig. 1) to justify the potential existence of the seasonality of ocean tides, particularly in the Siberian continental shelf (e.g., Sea of Okhotsk and Bering Sea) and northern Atlantic ocean.

\section{SEASONAL OCEAN TIDES DETERMINATION OVER THE SUBARCTIC OCEAN AND RESULT}

Because of the potential seasonality of ocean tidal signals from the above results, we make an attempt to conduct an empirical tidal analysis (Shum et al. 2006; Yi et al. 2006). The result is shown in Tables $2 a$ and $b$. The empirical tidal solution is generated based on a modified orthotide tidal analysis (Andersen 1994) for a regular gridded solution. Eight dominant short-period tides and four long-period tides (i.e., annual, semi-annual, $\mathrm{M}_{\mathrm{f}}$ and $\mathrm{M}_{\mathrm{m}}$ ) along with a bias term corresponding to each satellite track are simultaneously estimated (Yi et al. 2006).
All SSH anomaly data from the abovementioned description, except for the Jason-2 data used for the independent tide model validations, were included to generate the seasonal ocean tide solutions here. Note that the seasonallyseparated SSH anomaly data, instead of all SSH anomaly data, were utilized in the iterative tidal solution process (Fok 2012). The data amount per grid point is sufficient for seasonal ocean tidal solution robustness owing to the altimeter tracks converging in the polar ocean (Fig. 2). The number of observations ranges from 250 to 18000 for both the seasons.

To mitigate the tidal aliasing error and improve spatial coherence, those SSH anomaly data with ground tracks fall within a predefined square area of $0.75^{\circ} \times 0.75^{\circ}$ were included to generate the corresponding solution at the grid center (Smith 1999) with $0.25^{\circ} \times 0.25^{\circ}$ grid resolution. Spatial interpolation was used to generate gridded locations without data or where only Envisat data are available. Ra- 
diational potential and free core nutation $(\mathrm{FCN})$ resonance effects were taken into account in the solution process (Matsumoto et al. 2000). The tidal solution process is similar to the solutions obtained by Fok (2012). As opposed to using either spatial or temporal weighting applied to the leastsquares tidal solution, both spatial and temporal weighting were simultaneously considered. An outlier down-weighting scheme was also considered.

In general, all ocean tidal constituents respond differently in the presence of seasonal sea ice cover. A few cen- timeter change in amplitudes and tens of degree change in phases are observed for most regions that agree well with the findings from Kagan et al. (2011) for $\mathrm{M}_{2}$ tide, except around the Chukchi Sea near the eastern Siberia region where noticeable spatial changes in $\mathrm{M}_{2}, \mathrm{~S}_{2}$, and $\mathrm{K}_{1}$ tidal amplitudes and phases have been observed, particularly for $\mathrm{S}_{2}$ and $\mathrm{K}_{1}$ tides at latitudes higher than $66^{\circ}$ (Figs. 3 and 4 ).

In principle, the presence of sea ice should provide a damping effect on ocean tidal amplitudes and thus an increase in tidal phases (Kagan et al. 2008). However, the
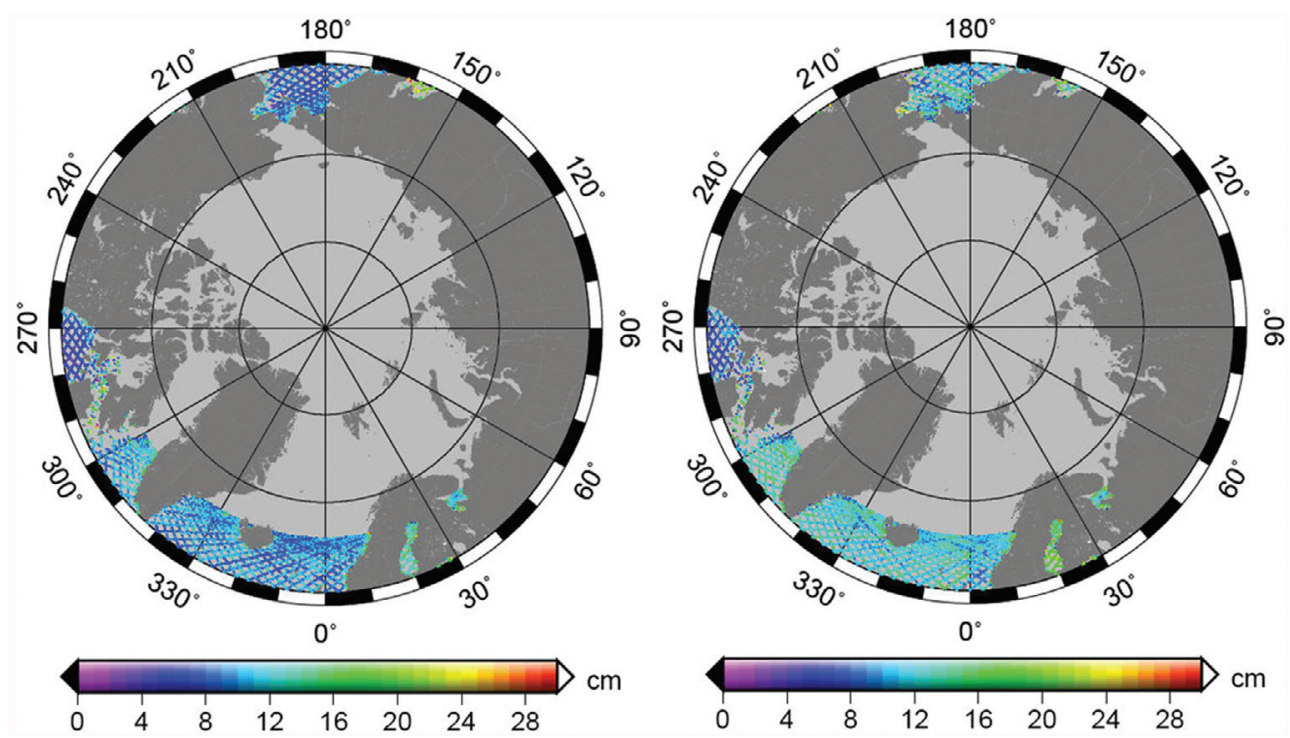

Fig. 1. Standard deviation of SSH anomaly residuals during summer season (left) and during winter season (right) for Jason-2 altimeter data (cycles 1 - 66) over Subarctic Ocean with ocean tides corrected using a forward global ocean tide model (e.g., GOT4.7), indicating the potential seasonality of ocean tides. Note that winter season is defined between September and March, whereas summer season is defined between March and September.
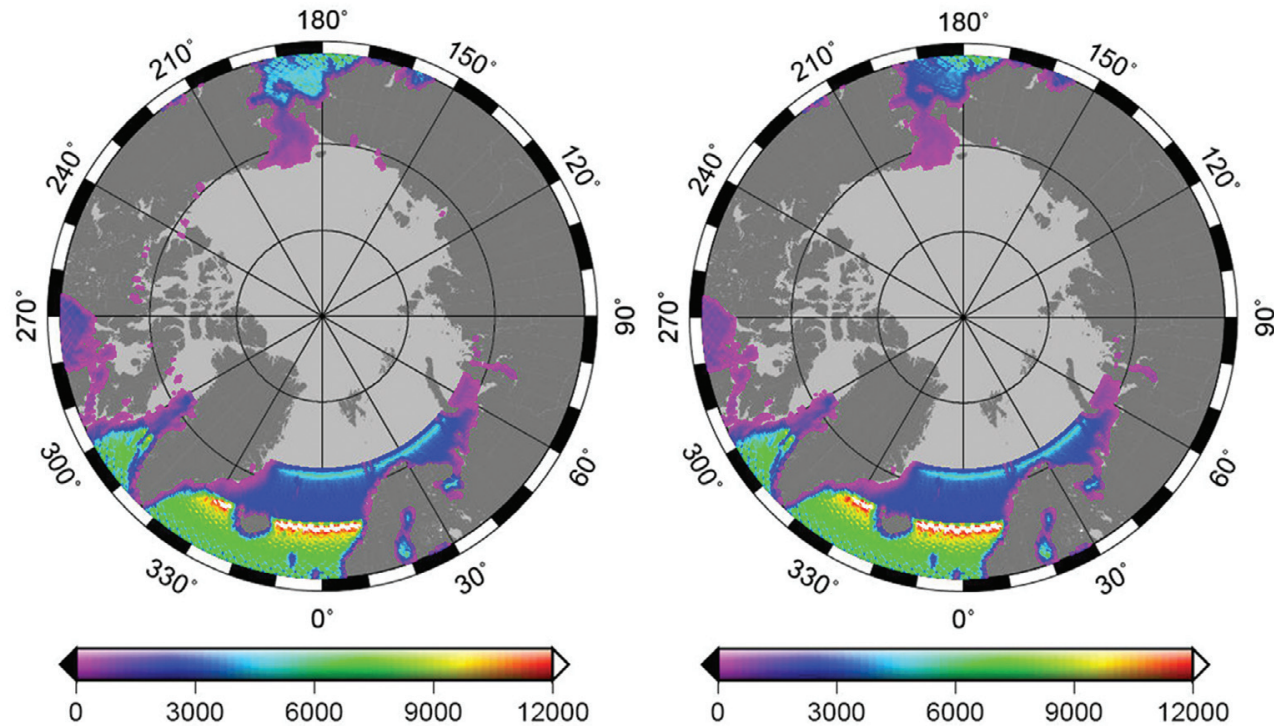

Fig. 2. Number of observations per grid used for the incremental tidal analysis solution during summer season (left) and during winter season (right). Note that GOT4.7 model serves as the initial model for latitude higher than $66^{\circ}$. 

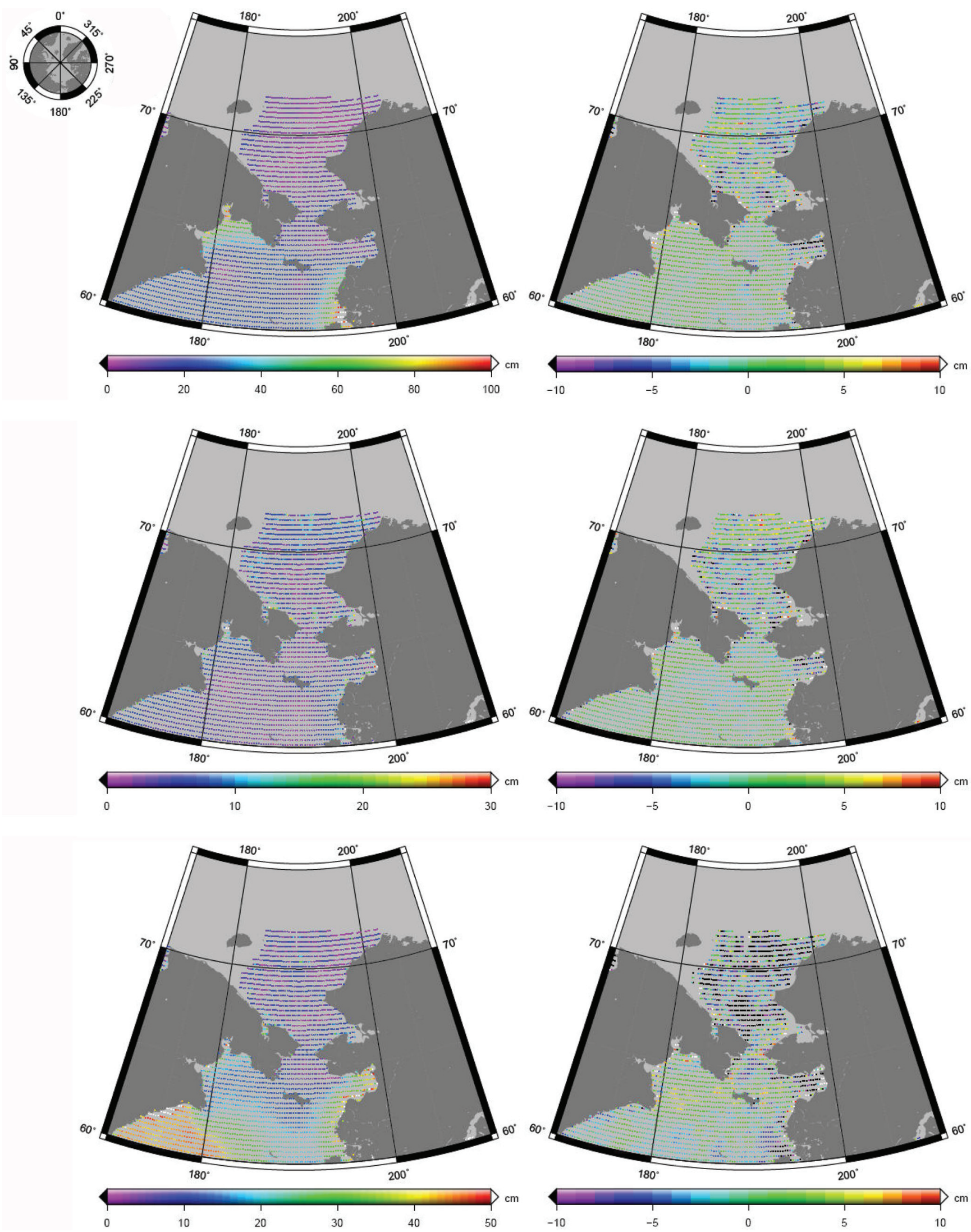

Fig. 3. Amplitudes of $\mathrm{M}_{2}$ (top) and $\mathrm{S}_{2}$ (middle) and $\mathrm{K}_{1}$ (bottom) tides during summer season (left) and their differences with that during winter season (right) over the Subarctic Ocean. Note that the positive difference indicates the amplitude in summer season is larger than that of winter. 

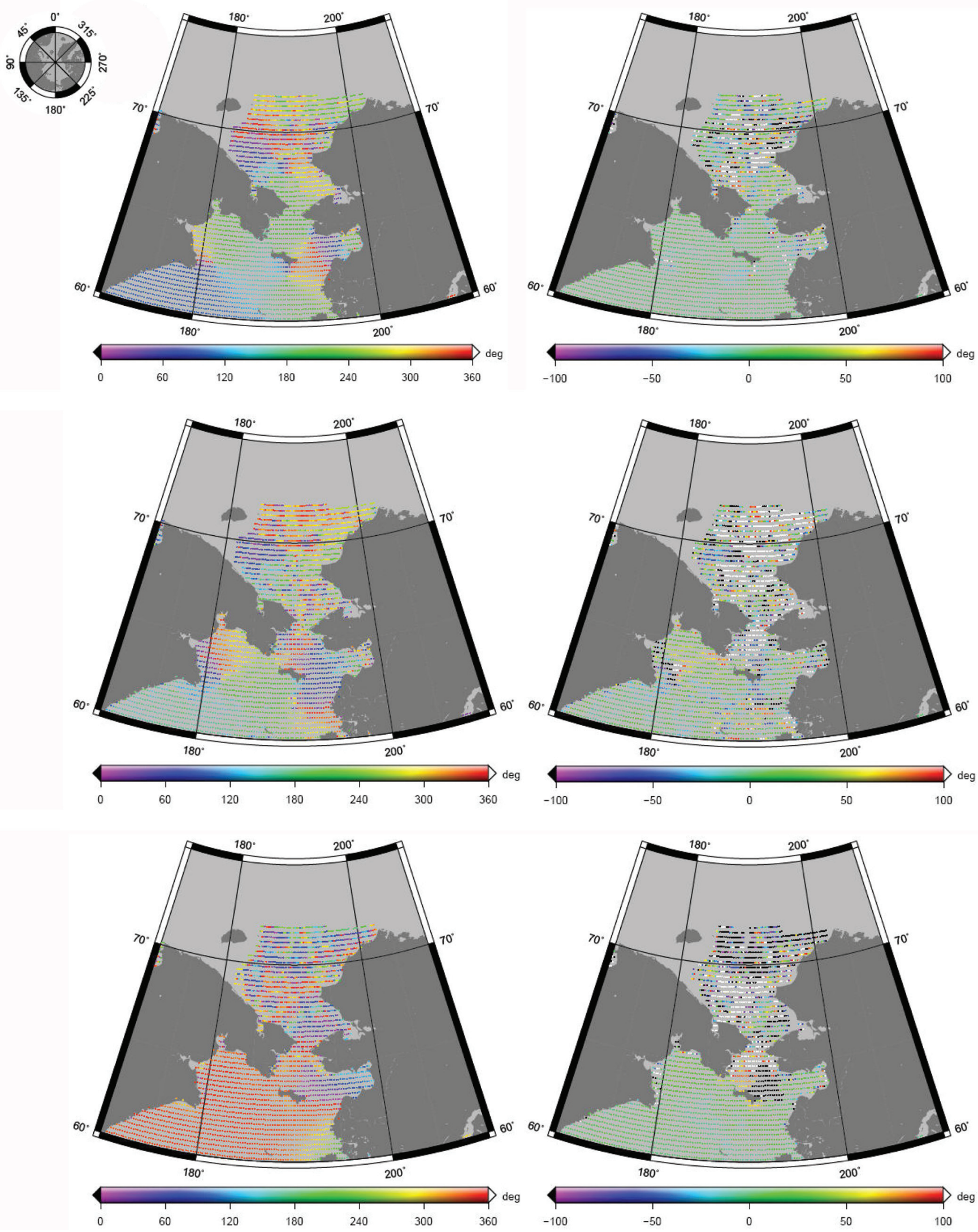

Fig. 4. Phase of $\mathrm{M}_{2}$ (top) and $\mathrm{S}_{2}$ (middle) and $\mathrm{K}_{2}$ (bottom) tides during summer season (left) and their difference with that during winter season (right) over Subarctic Ocean. 
seasonal ocean tides determined from altimeter observations reveals that the $\mathrm{M}_{2}, \mathrm{~S}_{2}$, and $\mathrm{K}_{1}$ tidal amplitudes increase during the winter season when compared to that in summer. Note that the positive difference in amplitude represents the tidal amplitude in the summer season is larger than that in winter for a better interpretation (Fig. 3). The change in tidal amplitudes can be larger than $10 \mathrm{~cm}$, whereas the tidal phase varies significantly around the region. We speculate that the variations in tidal solutions or the larger observed winter tide amplitudes could be due to a substantial amount of seasonal sea ice freeboard movement around the region, presumably due in part to energetic ocean dynamics, with evidence that the spatial extent of sea ice has been observed to be changing rapidly every month [see Figs. 7.8 to 7.13, Renganathan (2010) and from National Snow and Ice Data Center (NSIDC)].

A SSH anomaly variance reduction test was also conducted for the seasonal tides (Tables 2a and b). Substantial improvement in the variance reduction in all altimeter data during the summer season was observed when compared to the empirical model without seasonal tides determination in this study, except TOPEX and Jason- 2 altimeter data which is primarily due to $\pm 66^{\circ}$ coverage whereas our investigation focuses on a higher latitude region. Large variation was presented for all altimeter data during the winter season compared to that of summer. Only GFO and Envisat demonstrated an improvement during winter probably due to the fact that major tidal variation occurred around the Chukchi Sea where the latitude is higher than $66^{\circ}$ to which TOPEX/ Jason series altimeters belong. Hence, the GFO and Envisat altimeter observations are more sensitive to the tidal amplitude and phase change due to the presence of sea ice.

\section{CONCLUSIONS}

This paper investigated the potential presence of seasonal variations in ocean tides in the Subarctic Ocean. The result provides evidence for seasonal tidal patterns demonstrated using the variance reduction analysis for altimeter SSH residual anomaly data during the summer and winter seasons. The subsequent empirical seasonal (winter and summer) ocean tide model, separately derived from satellite altimetry data, provided both qualitative and quantitative explanation on the seasonal tidal pattern, in particular around the Chukchi Sea near the eastern Siberia region where the seasonal movement of large amounts of sea ice freeboards does contribute to the changes in the tidal amplitudes and phases of $\mathrm{M}_{2}, \mathrm{~S}_{2}$, and $\mathrm{K}_{1}$ tides. This result also justifies the necessity for an improved mean sea surface model to produce more accurate satellite altimetry sea surface height anomaly data, which in turn will allow advancement of ocean tide models accounting for seasonality in the Arctic Ocean.
Acknowledgements This research is partially funded by JPL 1384376, University of Colorado 154-5322, both in support of the NASA Surface Water and Ocean Topography satellite mission, NASA Geodetic Image program NNX12AQ07G, Ohio State University's Climate, Water, and Carbon program, and the Chinese Academy of Sciences/ SAFEA International Partnership Program for Creative Research Teams (KZZD-EW-TZ-05). The satellite altimeter data products are from NASA via JPL PO-DAAC, US Navy via NOAA/LSA, ESA/ESRIN, and CNES/AVISO. Part of the figures in the paper is generated using GMT (Wessel and Smith 1998). We thank the ocean tidal modelers for providing their models which were used in this study.

\section{REFERENCES}

Andersen, O. B., 1994: Ocean tides in the northern North Atlantic and adjacent seas from ERS 1 altimetry. J. Geophys. Res., 99, 22557-22573, doi: 10.1029/94JC01433. [Link]

Bosch, W. and R. Savcenko, 2008: EOT08a, empirical ocean tide model from multi-mission satellite altimetry - EOT08a performance in coastal areas. Report No. 81, Deutsches Geodätisches Forschungsinstitut (DGFI), München, Germany.

Campin, J.-M., J. Marshall, and D. Ferreira, 2008: Sea iceocean coupling using a rescaled vertical coordinate $z^{*}$. Ocean Model., 24, 1-14, doi: 10.1016/j.ocemod.2008. 05.005. [Link]

Cartwright, D. E. and A. C. Edden, 1973: Corrected tables of tidal harmonics. Geophys. J. Int., 33, 253-263, doi: 10.1111/j.1365-246X.1973.tb03420.x. [Link]

Cheng, Y. and O. B. Andersen, 2011: Multimission empirical ocean tide modeling for shallow waters and polar seas. J. Geophys. Res., 116, C11001, doi: 10.1029/20 11JC007172. [Link]

Cheng, Y., O. B. Andersen, and P. Knudsen, 2012: First evaluation of MyOcean altimetric data in the Arctic Ocean. Ocean Sci. Discuss., 9, 291-314, doi: 10.5194/ osd-9-291-2012. [Link]

Egbert, G. D. and S. Y. Erofeeva, 2002: Efficient inverse modeling of barotropic ocean tides. J. Atmos. Ocean. Technol., 19, 183-204, doi: 10.1175/1520-0426(2002) 019<0183:EIMOBO>2.0.CO;2. [Link]

Fok, H. S., 2012: Ocean tides modeling using satellite altimetry. Ph.D. Dissertation, School of Earth Sciences, Ohio State University, Ohio, USA.

Fok, H. S., H. B. Iz, C. K. Shum, Y. Yi, O. Andersen, A. Braun, Y. Chao, G. Han, C. Y. Kuo, K. Matsumoto, and Y. T. Song, 2010: Evaluation of ocean tide models used for Jason-2 altimetry corrections. Mar. Geodesy, 33, 285-303, doi: 10.1080/01490419.2010.4910 27. [Link] 
Fu, L. L., E. J. Christensen, C. A. Yamarone, M. Lefebvre, Y. Ménard, M. Dorrer, and P. Escudier, 1994: TOPEX/ POSEIDON mission overview. J. Geophys. Res., 99, 24369-24381, doi: 10.1029/94JC01761. [Link]

Hibler III, W. D. and K. Bryan, 1984: Ocean circulation: Its effects on seasonal sea-ice simulations. Science, 224, 489-492, doi: 10.1126/science.224.4648.489. [Link]

Holloway, G. and T. Sou, 2002: Has Arctic sea ice rapidly thinned? J. Climate, 15, 1691-1701, doi: 10.1175/1520 -0442(2002)015<1691:HASIRT>2.0.CO;2. [Link]

Huess, V. and O. B. Andersen, 2001: Seasonal variation in the main tidal constituent from altimetry. Geophys. Res. Lett., 28, 567-570, doi: 10.1029/2000GL011921. [Link]

Kagan, B. A., D. A. Romanenkov, and E. V. Sofina, 2008: Tidal ice drift and ice-generated changes in the tidal dynamics/energetics on the Siberian continental shelf. Cont. Shelf Res., 28, 351-368, doi: 10.1016/j.csr.2007. 09.004. [Link]

Kagan, B. A., E. V. Sofina, and A. A. Timofeev, 2011: Modeling of the $M_{2}$ surface and internal tides and their seasonal variability in the Arctic Ocean: Dynamics, energetics and tidally induced diapycnal diffusion. J. Mar. Res., 69, 245-276, doi: 10.1357/0022240117987653 12. [Link]

Kruizinga, G., 1997: Validation and applications of satellite radar altimetry. Ph.D. Dissertation, University of Texas at Austin, Texas, USA.

Kwok, R. and N. Untersteiner, 2011: The thinning of Arctic sea ice. Phys. Today, 64, 36-41, doi: 10.1063/1.35804 91. [Link]

Leeuwenburgh, O., O. B. Andersen, and V. Huess, 1999: Seasonal tide variations from tide gauges and altimetry. Phys. Chem. Earth A, 24, 403-406, doi: 10.1016/ S1464-1895(99)00049-6. [Link]

Lyard, F., F. Lefevre, T. Letellier, and O. Francis, 2006: Modelling the global ocean tides: modern insights from FES2004. Ocean Dyn., 56, 394-415, doi: 10.1007/s 10 236-006-0086-x. [Link]

Matsumoto, K., T. Takanezawa, and M. Ooe, 2000: Ocean tide models developed by assimilating TOPEX/POSEIDON altimeter data into hydrodynamical model: A global model and a regional model around Japan. $J$. Oceanogr., 56, 567-581, doi: 10.1023/A:10111572125 96. [Link]

Padman, L. and S. Erofeeva, 2004: A barotropic inverse tidal model for the Arctic Ocean. Geophys. Res. Lett., 31, L02303, doi: 10.1029/2003GL019003. [Link]

Pidwirny, M., 2006: Introduction to the Oceans, Fundamentals of Physical Geography, $2^{\text {nd }}$ Edition, available at http://www.physicalgeography.net/fundamentals/80. $\underline{\mathrm{html}}$.

Ray, R. D., 1999: A global ocean tide model from TOPEX/ POSEIDON altimetry: GOT99.2 (NASA/TM), National Aeronautics and Space Administration, Goddard Space Flight Center, 58 pp.

Ray, R. D., 2006: Secular changes of the $\mathrm{M}_{2}$ tide in the Gulf of Maine. Cont. Shelf Res., 26, 422-427, doi: 10.1016/ j.csr.2005.12.005. [Link]

Ray, R. D., G. D. Egbert, and S. Y. Erofeeva, 2011: Tidal predictions in shelf and coastal waters: status and prospects. In: Vignudelli, S., A. Kostianoy, P. Cipollini, and J. Benveniste (Eds.), Coastal Altimetry, Springer, 191-216.

Renganathan, V., 2010: Arctic sea ice freeboard heights from satellite altimetry. Ph.D. Dissertation, Department of Geomatics Engineering, University of Calgary, Calgary, Canada.

Shum, C. K., J. C. Ries, and B. D. Tapley, 1995: The accuracy and applications of satellite altimetry. Geophys. J. Int., 121, 321-336, doi: 10.1111/j.1365-246X.1995. tb05714.x. [Link]

Shum, C. K., P. L. Woodworth, O. B. Andersen, G. D. Egbert, O. Francis, C. King, S. M. Klosko, C. Le Provost, X. Li, J.-M. Molines, M. E. Parke, R. D. Ray, M. G. Schlax, D. Stammer, C. C. Tierney, P. Vincent, and C. I. Wunsch, 1997: Accuracy assessment of recent ocean tide models. J. Geophys. Res., 102, C11, 25173-25194, doi: 10.1029/97JC00445. [Link]

Shum, C. K., N. Yu, and C. S. Morris, 2001: Recent advances in ocean tidal science. J. Geod. Soc. Jpn., 47, 528-537.

Shum, C. K., Y. C. Yi, H. K. Li, K. Matsumoto, T. Sato, X. C. Wang, Y. Chao, X. L. Deng, and H. B. Iz, 2006: Coastal ocean tide modeling using satellite altimetry. Ocean Surface Topography Science Team (OSTST) Meeting, Venice, Italy.

Smith, A. J. E., 1999: Application of satellite altimetry for global ocean tide modeling. Ph.D. Dissertation, Delft Institute for Earth-Oriented Space Research, Delft University Press.

Wessel, P. and W. H. F., Smith, 1998: New, improved version of generic mapping tools released. Eos, Trans., $A G U, 79$, p 579, doi: 10.1029/98EO00426. [Link]

Yi, Y., 2010: The Ohio State University stackfiles for satellite radar altimeter data. Report No. 495, Geodetic Science, School of Earth Sciences, Ohio State University.

Yi, Y., K. Matsumoto, C. K. Shum, Y. Wang, and R. Mautz, 2006: Advances in southern ocean tide modeling. $J$. Geodyn., 41, 128-132, doi: 10.1016/j.jog.2005.08.022. [Link] 